\title{
TESTANDO O TRIÂNGULO DE CRESSEY NO CONTEXTO DA CONVERGÊNCIA ÀS NORMAS INTERNACIONAIS DE CONTABILIDADE: UM ESTUDO EMPÍRICO SOBRE COMPORTAMENTO ÉTICO DE PROFISSIONAIS DE CONTABILIDADE
}

\author{
TESTING THE TRIANGLE CRESSEY IN THE CONTEXT OF \\ CONVERGENCE WITH INTERNATIONAL ACCOUNTING \\ STANDARDS: AN EMPIRICAL STUDY ON THE ETHICAL BEHAVIOR \\ OF ACCOUNTING PROFESSIONALS
}

Data de submissão: 07/10/2013 Aceite: 05/04/2014

Sidmar Roberto Vieira Almeida ${ }^{1}$ Francisco José dos Santos Alves ${ }^{2}$

\section{RESUMO}

O objetivo deste estudo foi verificar como o profissional de contabilidade se posiciona em relação aos dilemas morais, envolvendo atos ilícitos e o Triângulo de Cressey no exercício de sua atividade profissional, no ambiente de convergência aos padrões internacionais de Contabilidade. Buscaram-se identificar quais os componentes deste triângulo e que características individuais influenciam a intenção de agir deste profissional. Também foi avaliado se havia flexibilidade na escolha de práticas contábeis propiciada pela convergência aos padrões internacionais de Contabilidade. Os resultados corroboraram com o demonstrado no Modelo de Cressey, na medida em que sugeriram dentro dos cenários propostos, que os profissionais de contabilidade se aproveitariam de uma eventual troca da empresa de auditoria, para efetuar ajustes que beneficiassem o resultado da Companhia (Oportunidade), e justificariam este procedimento, pelo fato de ser uma prática comum no mercado (Racionalização), tentando transformar algo antiético em algo aceitável. Pôde-se verificar que as variáveis: julgamento do ato e gravidade do ato, foram estatisticamente significantes em relação à intenção de agir do profissional contábil. Já a flexibilidade não apresentou significância estatística.

Palavras-Chave: Ética. Tomada de Decisão. Triângulo de Fraude. Normas Internacionais de Contabilidade.

\footnotetext{
${ }^{1}$ Possui graduação em Administração pela Universidade Federal do Rio de Janeiro - UFRJ, graduação em Ciências Contábeis pela Universidade do Estado do Rio de Janeiro - UERJ e mestrado em Ciências Contábeis pela Universidade do Estado do Rio de Janeiro - UERJ. Atualmente é Professor da Universidade Estadual do Rio de Janeiro. Rio de Janeiro. Rio de Janeiro. Brasil. E-mail: sid.adm@ig.com.br

${ }^{2}$ Possui graduação em Ciências Contábeis pela Universidade do Estado do Rio de Janeiro - UERJ, mestrado em Ciências Contábeis pela Universidade do Estado do Rio de Janeiro - UERJ e doutorado em Controladoria e Contabilidade pela Universidade de São Paulo - USP. Atualmente é professor da Universidade do Estado do Rio de Janeiro. Rio de Janeiro. Rio de Janeiro. Brasil. E-mail: fjalves@globo.com
} 


\begin{abstract}
The aim of this study was to verify how the accounting professional is positioned in relation to moral dilemmas involving torts and Triangle Cressey in the exercise of their professional activity in the convergence to international standards of accounting environment. We sought to identify which components of the triangle and which individual characteristics influence the intention of this act professional. We also assessed whether there was flexibility in the choice of accounting practices brought about by the convergence of international accounting standards. The results corroborate the model shown in Cressey in that it suggested that the proposed scenarios accounting professionals would take advantage of a moment of exchanging the firm to make adjustments that will benefit the Company's results (Opportunity), trying to justify this procedure because it is a common practice in the market (Rationalization), trying to turn something into something unethical acceptable. It was verified that the variables act of judgment and severity of the act were also statistically significant in relation to the intention to act the accounting professional. Have the flexibility not statistically significant.
\end{abstract}

Keywords: Ethics. Decision Making.Fraud Triangle. International Accounting Standards.

\title{
1 INTRODUÇÃO
}

O sistema contábil brasileiro sofreu profundas mudanças a partir do ano de 2007. Com a promulgação da Lei $n^{\circ} 11.638$ de 28 de dezembro de 2007, ficou estabelecido que as normas contábeis brasileiras passariam a utilizar o padrão contábil definido pelo IASB (International Accounting Standards Board), através do IFRS (International Financial Reporting Standards), seguindo um grande movimento mundial de harmonização das práticas contábeis.

Estes padrões internacionais de Contabilidade propiciaram flexibilidade na escolha das práticas contábeis, influenciadas cada vez mais por características consensuais do que características rígidas. Santos (2010) afirma que, de maneira geral, há o encorajamento para a adoção de diretrizes mais focadas em julgamentos, em detrimento às regras mais detalhadas.

Tais mudanças acabaram valorizando a profissão contábil, na medida em que cresce o envolvimento dos profissionais de contabilidade nas tomadas de decisões financeiras e estratégicas em âmbito empresarial. Cada vez mais, os relatórios confeccionados pelas áreas especializadas em negócios impactam, os usuários externos da informação, que exigem transparência e confiabilidade no universo contábil-financeiro. Pois, pautados nas informações disponibilizadas pela Contabilidade, investidores, administradores e acionistas tomam decisões. Portanto, os aspectos éticos devem ser levados em consideração pelo profissional de contabilidade ao elaborar Demonstrações Financeiras de uma empresa, dado o grau de influência que estas informações possuem.

Esta preocupação mergulha no campo das informações e registros; na manutenção e preservação da confiança das empresas, investidores e da sociedade como um todo, e, em especial na responsabilidade civil, fiscal, social e ética dos profissionais de Contabilidade, constantemente, contestadas quando a deteç̧ão de atos ilícitos vem a público. Os profissionais do segmento contábil, frequentemente, deparam-se com dilemas éticos, que para serem solucionados exigem a observância dos princípios que regem a categoria.

Sendo assim, o objetivo deste estudo foi verificar como o profissional de contabilidade se posiciona em relação aos dilemas morais, que envolvem atos ilícitos e o Triângulo de Cressey, no exercício de sua atividade profissional, em um ambiente de convergência aos padrões internacionais de Contabilidade. Neste âmbito, buscou-se identificar quais os componentes deste triângulo e quais as características individuais, que influenciam a intenção de agir deste profissional. Também foi avaliado se havia flexibilidade na escolha de práticas contábeis, propiciada pela convergência aos padrões internacionais de Contabilidade. 
Considera-se este estudo relevante, pois, devido ao pouco tempo transcorrido, a partir dessas mudanças, em um momento de convergência às Normas Internacionais de Contabilidade, estudos relacionados à conduta ética dos profissionais de Contabilidade, no que tange aos processos de tomada de decisão, no Brasil, ainda têm sido pouco explorados.

Este estudo está estruturado da seguinte forma: a segunda seção aborda brevemente o processo de implantação das normas internacionais no Brasil, abrangendo aspectos éticos e morais deste processo, a terceira seção expõe a metodologia adotada e a seleção da amostra, a quarta seção aborda os resultados e na quinta seção encontram-se as considerações finais.

\section{REFERENCIAL TEÓRICO}

\subsection{Breve Histórico do IFRS no Brasil}

Diversos países do mundo promoveram ações conjuntas objetivando a convergência contábil, através da implementação dos International Financial Reporting Standards (IFRS). O International Accounting Standards Board (IASB) é o órgão responsável pela condução desse processo por meio da formulação de normas que devem ser seguidas durante a preparação das demonstrações contábeis, para que a convergência contábil ocorra de forma correta e abrangente. Todavia, este processo enfrenta entraves para ser operacionalizado, conforme alerta Callao (2010) ao destacar dificuldades relacionadas às peculiaridades enraizadas na cultura local, o que acaba prejudicando o movimento em busca da harmonização.

Como forma de auxiliar esse processo de mudança no Brasil, o Comitê de Pronunciamentos Contábeis (CPC) editou vários pronunciamentos, no sentido de possibilitar a emissão de normas pelas entidades reguladoras, orientando o seu cumprimento, na tentativa de facilitar este processo. No caso brasileiro, houve uma mudança em relação aos padrões contábeis, os quais eram influenciados por aspectos legais ("code-law"), e, com a implementação dos padrões internacionais, passaram a ter um caráter menos legal e mais consensual ("commom-law").

De acordo com Martins, Martins e Martins (2007), antes da implementação dos padrões internacionais, o processo de regulamentação era elaborado quase exclusivamente pelo poder executivo e legislativo, com participação mínima dos contadores e usuários da informação contábil, em um processo de cima para baixo.

Assim, o processo de convergência brasileiro ocorreu em duas etapas, conforme está esquematizado na Figura 1, a seguir.

Figura 1: Esquema gráfico das alterações das normas contábeis no Brasil

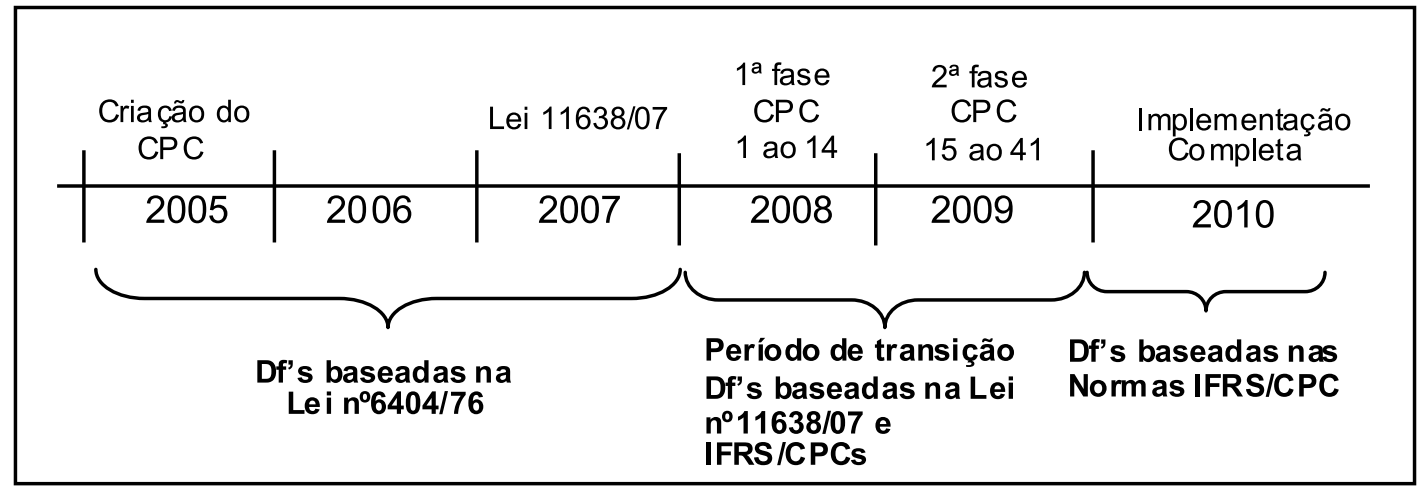

Fonte: Almeida, Costa e Silva (2011) 
A primeira fase de implementação das normas internacionais de contabilidade se restringiu a aplicação dos CPCs, até então divulgados (1 ao 14) ,que regulamentou aspectos da nova Lei para o ano de 2008 e facultou para as empresas a adoção para o ano de 2007, de acordo com o CPC 13. A segunda fase ocorreu no ano de 2009, quando foram emitidos os demais CPCs, Pronunciamentos, Interpretações e Orientações, com vigência para os exercícios sociais, tiveram início a partir de 1 을 de janeiro de 2010.

\subsubsection{Desdobramentos oriundos da convergência aos padrões internacionais de contabilidade}

Com características mais consensuais e menos rígidas, a convergência aos Padrões Internacionais de Contabilidade pode influenciar o processo decisório da escolha de práticas contábeis, através de fatores como os custos de agência, a assimetria de informações e custos de transação. Oliveira e Bispo $(2009$, p.2) afirmam que "Aproveitando-se da assimetria de informações existente, os gestores podem, por exemplo, utilizar escolhas contábeis por razões oportunistas, gerando conflitos nas organizações, porque acabam por interferir no resultado da empresa [...]".

Estas questões oportunistas ficam mais perceptiveis, frente a um cenário em que não há leis ou normas muito rígidas, que limitariam o profissional de contabilidade na utilização de determinados métodos e critérios, o que poderia abrir margem para que ocorra um gerenciamento de resultados através de possíveis flexibilidades, advindas da escolha das práticas contábeis do processo de convergência. Martinez (2001, p. 13) aprofunda o tema afirmando que "[...] nos pontos em que as normas contábeis facultam certa discricionariedade para o gerente, este realiza suas escolhas não em função do que dita à realidade concreta dos negócios, mas em função de outros incentivos, que o levam a desejar reportar um resultado distinto". Arruda, Madruga e Junior (2008) indicam que, através de um sistema de controle interno aprimorado e confiável, há uma tendência de que estes incentivos sejam inibidos, o que propicia maior segurança para os administradores e para os investidores. Pressões externas e internas da organização podem originar tais manipulações. Estas razões motivaram esta pesquisa e a reflexão sobre a conduta dos profissionais de Contabilidade no âmbito da ética.

\subsubsection{Influências éticas no processo de tomada de decisões}

Neste processo de desvio de conduta, características individuais ou coletivas, que podem influenciar as escolhas durante o processo decisório, devem ser analisadas dentro do ambiente empresarial , considerando outras influências, tais como a cultura organizacional, relações com os pares, códigos de ética e outros. Pereira, Lobler e Simonetto $(2001$, p.268) destacam que “Um processo de decisão é um sistema de relações entre elementos de natureza objetiva e elementos de natureza subjetiva. Este sistema é indivisível e, portanto, quando se enfoca processo decisório não se pode negligenciar nenhum destes dois aspectos".

No caso específico da contabilidade, onde os relatórios são importantes meios para as decisões, Martinez (2001) aduz que, as manipulações nas demonstrações financeiras comprometem a qualidade da informação contábil e, consequentemente, a tomada de decisão, podendo afetar a forma pela qual os investimentos são alocados entre empresas, bem como provocar distribuições de riquezas injustificáveis. Investidores mais bem informados podem aumentar a sua riqueza à custa de investidores menos informados. Sunder (2002) sugere que neste conflito, o comportamento dos gestores pode ser conflitante com o interesse dos stakeholders, uma vez que a divulgação pode privilegiar seus próprios interesses. 
Segundo Douglas, Davidson e Schwartz (2001, p.104), "A cultura ética da organização ou, mais especificamente, o ambiente ético dentro da empresa, criado com as práticas de gestão e os valores desposados, pode ser o mais importante elemento impeditivo do comportamento antiético."

Assim, inúmeros são os fatores que podem influenciar o processo de tomada de decisão. Para Ferrell, Fraedrich e Ferrell (2001, p.98), "[...] o tomador de decisões que se associa a quem se comporta de maneira antiética, tem maior probabilidade de agir do mesmo modo".

Nesta pesquisa, serão consideradas as características individuais (idade, gênero, nível educacional, posição no mercado de trabalho) e situacionais, nas quais serão explorados os aspectos contidos no triângulo de fraudes de Cressey.

O modelo de Cressey é importante instrumento para explicar os fatores que motivam a ocorrência de fraude. Segundo Silva (2009), é "o modelo mais amplamente aceito para explicar os fatores que motivam um indivíduo a cometer a fraude, segundo os estudiosos [...]".

A combinação dos fatores pressão, racionalização e oportunidade foram denominadas, por Cressey, de "Triângulo da Fraude", conforme representado, abaixo, na Figura 2:

Figura 2: Triângulo de Fraude - Cressey

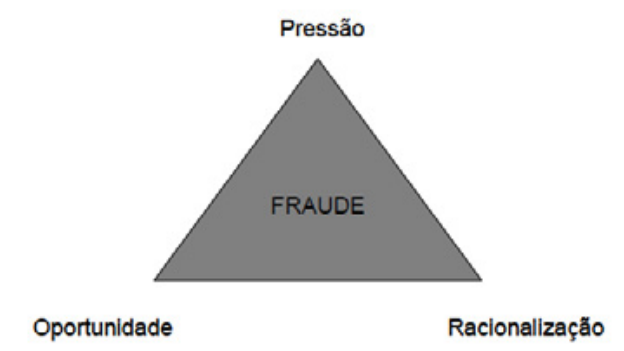

Fonte: Adaptado de SINGLETON, T.; JACK, B.. Fraud auditing and forensic accounting apud Silva (2009)

Os vértices do Triângulo da Fraude - pressão, racionalização, oportunidade - são as motivações, de acordo com Cressey, que levam um indivíduo a cometer uma fraude, sendo cada uma delas detalhadas abaixo:

- Pressão: O que leva um sujeito a cometer fraude, na maioria dos casos, é determinado pela necessidade econômica existente, seja pessoal ou familiar. Choo e Tan (2007) destacam que a pressão é influenciada pela situação da empresa e dos executivos. Empresas que constantemente atingem metas e expectativas, normalmente, não possuem tanta necessidade de fraudar seus demonstrativos financeiros, quando comparadas com empresas que passam por dificuldades.

- Oportunidade: corresponde à capacidade de cometimento da fraude, agindo de forma fraudulenta com um risco muito baixo de ser descoberto. Choo e Tan (2007) argumentam que os gestores irão buscar ativamente maneiras de criar meios de burlar os mecanismos institucionais criados para coibir a fraude, mesmo que as oportunidades não estejam presentes.

- Racionalização: O sujeito precisa encontrar uma justificativa pelas suas ações, para não ser visto como um fraudador. Choo e Tan (2007) citam que é mais fácil admitir a fraude como uma maneira aceitável de alcançar o sucesso quando há um ambiente social e corporativo, em que o lucro é perseguido a qualquer custo.

Deshmukh e Lewis (1997) indicam que, ao se realizar uma análise das variáveis normal- 
mente utilizadas em modelos de deteç̧ão de fraudes, constantemente, um dos três elementos do triângulo citado acima está presente; e, por isso, o mesmo é utilizado como ponto de partida para a seleção e organização de variáveis em diversos estudos.

De acordo com Turner et al. (2003), este triângulo possibilita uma combinação de diferentes fatores, de forma que, quando existem muitos incentivos para a fraude, até mesmo um gestor que, normalmente, é bastante ético poderá ser induzido a desconsiderar suas normas de comportamento.

O objetivo desta pesquisa, será verificar se há influência de cada um dos vértices do triângulo na intenção de agir do profissional de contabilidade, tomando-se como base um grupo de profissionais de contabilidade legalmente habilitados e com registro ativo no Conselho Regional de Contabilidade. Ademais, também será investigado se a convergência aos padrões internacionais de contabilidade propiciou flexibilidade na escolha de práticas contábeis. Amat $(1997$, p. 9) enxerga a Contabilidade Criativa como uma "[...] manipulação que se faz da informação contábil, aproveitandose dos vazios das normas existentes e as possíveis alternativas que tem o gerente à sua disposição sobre as diferentes práticas de avaliação utilizadas". Sendo assim, presume-se que quanto menor for a regulação, maior será a possibilidade de ocorrer manipulação da informação, seja ela legal ou ilegal.

Matsumoto e Parreira (2007, p. 4) exemplificam o gerenciamento de resultados como sendo "[...] a manipulação formal das contas de resultado ou da atividade operacional, mediante escolhas discricionárias de práticas e estimativas contábeis com implicações no resultado financeiro e em acordo com os princípios e as normas contábeis".

\section{METODOLOGIA}

\subsection{Seleção da Amostra}

Para alcançar os objetivos propostos no artigo, foram elaborados dois cenários que englobaram atitudes profissionais que pudessem ser influenciadas pelas práticas advindas da convergência às Normas Internacionais de Contabilidade. Os cenários são comumente utilizados para examinar julgamentos e intenções éticas em diferentes áreas (GOLES et al., 2006).

Em cada um dos dois cenários, foram formuladas perguntas contendo a Escala da Likert de 5 pontos, variando de ' 1 - Discordo Totalmente' até ' 5 - Concordo Totalmente', onde o valor 3 representa uma opinião neutra ou indiferente. Collis e Hussey $(2005$, p.174) destacam vantagens de utilizar-se a Escala de Likert, referindo que "[...] várias afirmações diferentes podem ser fornecidas numa lista que não toma muito espaço, é simples para o respondente completar e simples para o pesquisador codificar e analisar". Cada resposta recebeu uma classificação numérica que demonstra o grau de influência/impacto em relação à determinada atitude específica. As atitudes foram divididas em 8 itens e foram associadas a perguntas específicas no questionário, conforme apresentado abaixo:

1. Reconhecimento da questão moral: Procurou-se analisar de forma escalar, em cada cenário, se o profissional de contabilidade considera o dilema apresentado como de natureza ética.

2. Julgamento do ato: Procurou-se analisar de forma escalar, em cada cenário, o julgamento do profissional quanto à correção, ou não, da conduta apresentada no cenário.

3. Gravidade: Procurou-se analisar de forma escalar, em cada cenário, a percepção do respondente em relação à intensidade de gravidade dos atos em cada situação.

4. Oportunidade: Procurou-se analisar de forma escalar, em cada cenário, a percepção 
do respondente quanto à conduta a ser adotada em situações em que a variável oportunidade esteja presente.

5. Pressão: Procurou-se analisar de forma escalar, em cada cenário, a percepção do respondente quanto à pressão presente em cada situação.

6. Racionalização: Procurou-se analisar de forma escalar, em cada cenário, a percepção do respondente quanto à racionalização presente em cada situação.

7. Intenção em agir: Procurou-se analisar de forma escalar, em cada cenário, a percepção do respondente em relação à intenção de agir presente em cada situação.

8. Flexibilidade: Procurou-se analisar de forma escalar a percepção do respondente em relação á flexibilidade sobre a intenção de agir nas escolhas das práticas contábeis advindas da convergência aos padrões internacionais de contabilidade.

Para aumentar a confiabilidade dos instrumentos de pesquisa utilizados no estudo, as atitudes Reconhecimento da questão moral e Julgamento do ato, de forma conjunta, foram consideradas inconsistentes em 2 casos específicos. O primeiro, caso o respondente declarasse que concordava totalmente que não havia um problema moral, em cada um dos cenários, ele não poderia concordar totalmente que a conduta do profissional de contabilidade estava errada. No segundo, caso o respondente declarasse que discordava totalmente de que não havia um problema de ordem moral, em cada um dos cenários, ele não poderia discordar totalmente de que a conduta do profissional de contabilidade estava errada. Sendo encontrada tal inconsistência, o questionário referente ao cenário especificado será desconsiderado para fins estatísticos, todavia, continuará sendo utilizado na caracterização da amostra. Segundo Hair et al. (2005 p. 257), "Antes que os questionários possam ser usados, eles devem ser editados. Isso significa que devem ser inspecionados para que se verifiquem sua integridade e coerência. Algumas incoerências podem ser corrigidas nesse momento".

O primeiro cenário foi norteado pelo pronunciamento técnico CPC 06 - Operações de Arrendamento Mercantil. Para evitar que o passivo da empresa aumentasse, o profissional de contabilidade da empresa, no ato da elaboração de um contrato, incluiu cláusulas específicas que caracterizavam os arrendamentos mercantis da empresa como operacionais, mesmo que na essência estes arrendamentos fossem financeiros.

O segundo cenário foi norteado pelo pronunciamento técnico CPC 01 - Redução ao valor recuperável dos ativos. Para evitar despesas extras no resultado da Companhia, o contador defendeu a hipótese de não haver indícios de desvalorização dos ativos, mesmo que tenham ocorrido tais indícios.

Posto isso, foi empregado um questionário contendo 20 questões elaboradas com o intuito de avaliar a percepção dos respondentes em relação a cada cenário descrito. Estes questionários foram aplicados em um grupo de profissionais de contabilidade legalmente habilitados e com registro ativo no Conselho Regional de Contabilidade. A amostra foi composta por profissionais distribuídos em 18 empresas privadas, 8 empresas públicas e 5 escritórios de contabilidade, situados no Estado do Rio de Janeiro, nos quais existe relacionamento deste pesquisador com pelo menos um profissional de contabilidade em cada um destes estabelecimentos. A escolha dos informantes-chave se deu a partir da seleção de multiplicadores, que preenchiam os critérios estabelecidos pela pesquisa, em cada localidade: à medida que estes respondiam ao questionário, iam indicando outros pares, configurando uma amostra do tipo "bola de neve" ou "cascata" (MINAYO, 2004; BECKER, 2007). Inicialmente, foram enviados 31 e-mails diretamente às empresas escolhidas, sendo estes retransmitidos para outros profissionais, totalizando 782 e-mails enviados, no período de 13 de dezembro de 2012 a 13 de janeiro de 2013. 
Collis e Hussey (2005, p.151) destacam que este tipo de amostragem "é associada a estudos fenomenológicos, nos quais é essencial incluir pessoas com experiência dos fenômenos que estão sendo estudados na amostra", no caso desta pesquisa foram os profissionais de contabilidade. Em todos os e-mails, o pesquisador foi copiado para obter a fidedignidade do universo amostral e para que as respostas pudessem ser recebidas individualmente, evitando a dupla contagem dos questionários. Cada questionário foi analisado separado e confidencialmente, não havendo respostas certas ou erradas. A amostra utilizada conteve um total de 247 respondentes ( $32 \%$ do total de emails enviados). Adicionalmente, uma análise crítica foi feita para evitar qualquer distorção e inconsistência nos dados coletados. Dos 247 questionários coletados, 19 foram excluídos por apresentarem desconformidade .

Como resultado, foram considerados 228 questionários válidos para os testes de regressão logística. As informações coletadas foram codificadas, tabuladas e analisadas com apoio dos softwares Microsoft Excel e SPSS 17 (Statistical Package for the Social Sciences).

\subsection{Análise dos Resultados}

Para efetuar a apreciação dos dados, utilizou-se a análise estatística. Foram construídas tabelas de frequência, visando à ordenação dos dados. Cooper e Schindler (2003, p.366) destacam que este tipo de tabela "[...] ordena os dados atribuindo valores numéricos, com colunas para percentual $[\ldots . . . "$.

Utilizou-se a Regressão Logística Multivariada. Esta técnica pode ser classificada como técnica de dependência e de interdependência. Nesta pesquisa, optou-se pela técnica de dependência. Cooper e Schindler (2003, p.454) atestam que "se as variáveis de critério e predição estão presentes na questão de pesquisa, então teremos uma suposição de dependência". Optou-se por esta técnica, porque contempla múltiplas variáveis, visando à compreensão de relações complexas.

Foi utilizada no estudo a amostragem não probabilística, devido à inacessibilidade a toda a população. Levine et al., (2008) destacam que amostras não probabilística podem oferecer certas vantagens, tais como conveniência, velocidade e baixo custo. Os métodos de amostragem não probabilística devem ser utilizados exclusivamente para estudos em pequena escala, que precedam grandes investigações.

O nível de significância estatística utilizado na Regressão foi de $5 \%(0,05)$, sendo que alguns dados originais (variáveis não métricas) foram modificados para um novo formato (variáveis dicotômicas), quando da opção pela utilização da técnica de regressão múltipla. Esse fato ocorreu com a variável dependente intenção de agir (dummy). Desta forma, os respondentes que discordaram totalmente ou que discordaram parcialmente em relação aos cenários propostos foram agrupados como opção 1 . Os respondentes que concordaram totalmente ou concordaram parcialmente em relação aos cenários propostos foram agrupadas como opção 2. Os respondentes que se mostraram indiferentes em relação aos cenários propostos foram desconsiderados.

Abaixo é apresentada a variável dummy (intenção de agir), além de cada um dos problemas de pesquisa, Triângulo de fraudes (H1), Fatores individuais (H2) e Flexibilidade da norma (H3) com suas subdivisões. 
Figura 3: Variável dependente

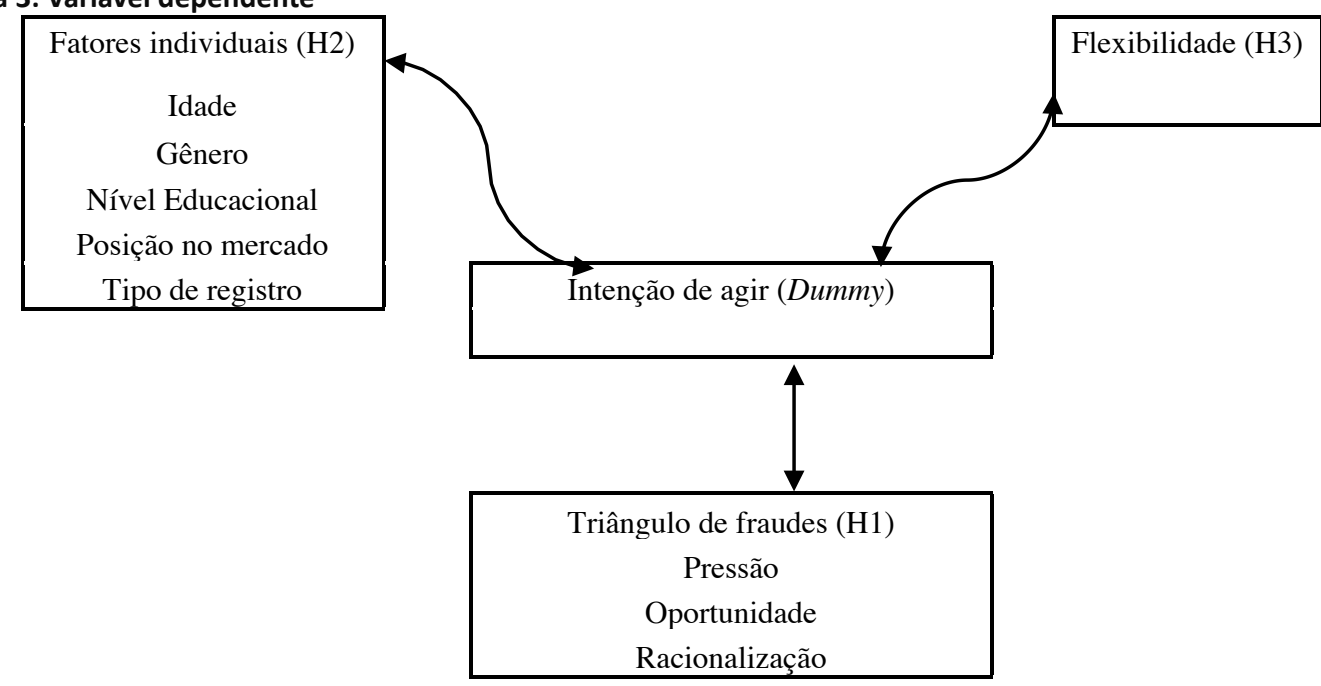

Fonte: $\mathrm{O}$ autor, 2013

Avaliou-se a Colinearidade das variáveis através do teste VIF, para verificar-se o grau de correlação entre as variáveis independentes. Quando as variáveis estão altamente correlacionadas, os coeficientes de regressão estimados podem flutuar, de forma abundante, de uma amostra para outra, fazendo com que seja arriscado interpretar os coeficientes como um indicador de importância relativa das variáveis de previsão. (COOPER e SCHINDLER, 2003). Um valor de referência comum é uma tolerância de 0,10 , o que corresponde a uma correlação múltipla de 0,95, valor este, utilizado no presente trabalho.

Para o ajuste geral das variáveis nos modelos, são elaborados dois testes: o teste Omnibus e o teste Hosmer e Lemeshow.

O software SPSS realiza dois testes para se avaliar o ajuste geral das variáveis no modelo. O primeiro é o teste de Omnibus dos coeficientes, o qual utiliza o valor do logaritmo da verossimilhança (-2LL). Se o resultado for significativo (valor $p<0,05)$, então as variáveis representam bem o modelo. O segundo teste aplicado foi o de Hosmer Lemeshow. Este teste mede a correspondência entre os valores reais e os previstos da variável dependente. Um melhor ajuste do modelo é apontado com uma menos diferença entre a classificação observada e a classificação prevista, indicado por um valor qui-quadrado não significante (valor $p>0,05)$. (ALVES, 2005, p. $144-145)$.

A combinação do teste de Hosmer e Lameshow com o teste geral do modelo de Omnibus fornece suporte para a aceitação do modelo (HAIR 2005), demonstrando que o modelo de regressão logística é significativo e adequado para o exame de suas variáveis.

\section{RESULTADOS}

\subsection{Estatística Descritiva da Amostra}

A amostra foi composta por 247 respondentes. A idade mínima dos respondentes foi de 22 anos e a máxima de 52 anos. A moda e a mediana foram de 30 anos, enquanto que a média foi de 32 anos. Deste total, $71 \%$ pertencem ao sexo masculino, e $29 \%$ ao sexo feminino, sendo 189 contadores (77\%) e 58 técnicos em contabilidade (23\%). Destes respondentes, menos de $10 \%$ são aposentados, autônomos ou empregadores. A grande maioria (72\%) trabalha no setor privado, 
seguido pelos trabalhadores do setor público (20\%).

Em relação ao nível de escolaridade, foi solicitado que o respondente informasse o grau de instrução mais alto obtido. Dos 247 respondentes, $61,9 \%$ são graduados, $27,5 \%$ são técnicos, $6,1 \%$ especialistas, $3,6 \%$ mestres e $0,8 \%$ doutores.

Tabela 1: Caracterização da amostra

\begin{tabular}{|c|c|c|c|c|c|}
\hline & & Frequência & $\%$ & \% Válido & $\%$ Cumulativo \\
\hline \multirow{3}{*}{ Gênero } & Homem & 176 & 71,3 & 71,3 & 71,3 \\
\hline & Mulher & 71 & 28,7 & 28,7 & 100,0 \\
\hline & Total & 247 & 100,0 & 100,0 & \\
\hline \multirow{6}{*}{ Nível Educacional } & Técnicos & 68 & 27,5 & 27,5 & 27,5 \\
\hline & Graduação & 153 & 61,9 & 61,9 & 89,5 \\
\hline & Especialização & 15 & 6,1 & 6,1 & 95,5 \\
\hline & Mestrado & 9 & 3,6 & 3,6 & 99,2 \\
\hline & Doutorado & 2 & 0,8 & 0,8 & 100,0 \\
\hline & Total & 247 & 100,0 & 100,0 & \\
\hline \multirow{6}{*}{$\begin{array}{l}\text { Mercado de } \\
\text { trabalho }\end{array}$} & Aposentado & 15 & 6,1 & 6,1 & 6,1 \\
\hline & Autônomo & 2 & 0,8 & 0,8 & 6,9 \\
\hline & Empregadores & 2 & 0,8 & 0,8 & 7,7 \\
\hline & Funcionário setor privado & 178 & 72,1 & 72,1 & 79,8 \\
\hline & Funcionário setor público & 50 & 20,2 & 20,2 & 100,0 \\
\hline & Total & 247 & 100,0 & 100,0 & \\
\hline \multirow{3}{*}{ Tipo de formação } & Contador & 189 & 76,5 & 76,5 & 76,5 \\
\hline & Técnico & 58 & 23,5 & 23,5 & 100,0 \\
\hline & Total & 247 & 100,0 & 100,0 & \\
\hline
\end{tabular}

Fonte: O autor, 2013.

No primeiro cenário proposto, conforme a deliberação CVM no 554 que aprovou o pronunciamento técnico CPC 06 - Operações de Arrendamento Mercantil, que aponta os dois tipos de arrendamento, "[...] é classificado como financeiro, se ele transferir substancialmente todos os riscos e benefícios inerentes à propriedade, [...] é classificado como operacional, se ele não transferir substancialmente todos os riscos e benefícios inerentes à propriedade".

Na elaboração de um contrato de arrendamento mercantil, o profissional de contabilidade incluiu cláusulas específicas que pudessem caracterizar o arrendamento como sendo operacional. Pela essência da operação, e pelas características do arrendamento, o mesmo deveria ter sido registrado como um arrendamento financeiro.Todavia, caso fosse registrado como arrendamento financeiro, o passivo da empresa (obrigações) aumentaria. Assim, as respostas obtidas foram as seguintes:

- Reconhecimento da questão moral: 158 respondentes discordaram com o fato de não haver um problema de ordem moral no cenário apresentado. Destes, $42 \%$ discordaram totalmente.

- Julgamento do ato: Dos questionados, 193 concordaram que a conduta do profissional de contabilidade estava errada. Concordaram totalmente 57\% da amostra, e 9 respondentes foram indiferentes.

- Gravidade do ato: Dos 247 respondentes, 178 concordaram com a gravidade da atitude do profissional de contabilidade no cenário proposto, $54 \%$ concordaram totalmente.

- Racionalização: Na questão, propiciou-se um ambiente de racionalização que justifi- 
casse o comportamento do profissional de contabilidade - atitude aceitável por estar dentro da legalidade, apesar de não representar a essência da operação, 166 dos respondentes discordaramdo comportamento do profissional, sendo que metade deles discordou totalmente.

- Pressão: Na questão, propiciou-se um ambiente no qual o profissional de contabilidade sofria algum tipo de pressão - alegação não haver bônus para nenhum funcionário caso o passivo fosse registrado, 210 respondentes discordaram da atitude do profissional de contabilidade, sendo que $70 \%$ discordaram totalmente.

- Intenção de agir: Quando é afirmado aos entrevistados que, dependendo da situação, eles poderiam agir da mesma maneira, 189 entrevistados discordaram de tal afirmação, sendo $36 \%$ totalmente e $41 \%$ parcialmente.

- Oportunidade: Foi proposta uma situação em que há uma oportunidade para que o profissional de contabilidade cometesse o ato - troca da empresa de auditoria sendo dificilmente descoberto. Nesse caso, $83 \%$ dos entrevistados discordaram do comportamento oportunista do profissional, sendo que $57 \%$ discordaram totalmente.

- Flexibilidade: Foi apresesentado o trecho da deliberação CVM no 554 que aprovou o pronunciamento técnico CPC 06 - Operações de Arrendamento Mercantil, "Um arrendamento mercantil é classificado como financeiro se ele transferir substancialmente todos os riscos e benefícios inerentes à propriedade. Um arrendamento mercantil é classificado como operacional se ele não transferir substancialmente todos os riscos e benefícios inerentes à propriedade". Afirmou-se que o referido trecho da norma é flexível. Nesse aspecto, 144 respondentes concordaram com a afirmação, sendo que $28 \%$ concordaram totalmente.

No segundo cenário, para evitar despesas extras no resultado da Companhia, o contador defendeu a hipótese de não haver indícios de desvalorização dos ativos, mesmo que tenham ocorrido tais indícios. Este cenário foi proposto com o intuito de englobar atitudes profissionais que pudessem ser influenciadas pelas práticas advindas da convergência às Normas Internacionais de Contabilidade na figura do pronunciamento técnico CPC 01 - Redução ao valor recuperável dos ativos. As respostas obtidas foram as seguintes:

- Reconhecimento da questão moral: 149 respondentes concordaram com o fato de não haver um problema de ordem moral no cenário apresentado. Destes, $30 \%$ concordaram totalmente.

- Julgamento do ato: Dos questionados, 202 concordaram que a conduta do profissional de contabilidade estava errada. Concordaram totalmente $59 \%$ da amostra.

- Gravidade do ato: Dos 247 respondentes, 183 afirmaram ser grave a atitude do profissional de contabilidade no cenário proposto; $61 \%$ concordaram totalmente.

- Racionalização: Na questão, propiciou-se um ambiente de racionalização que justificasse o comportamento do profissional de contabilidade - atitude aceitável por estar dentro da legalidade, apesar de não representar a essência da operação, 185 dos respondentes discordaram do o comportamento do profissional, sendo que $60 \%$ discordaram totalmente.

- Pressão: Na questão, propiciou-se um ambiente no qual o profissional de contabilidade sofria algum tipo de pressão - alegação de não haver bônus para nenhum funcionário caso a fosse registrada uma despesa com a desvalorização dos ativos, 208 res- 
pondentes discordaram da atitude do profissional de contabilidade, sendo que $72 \%$ discordaram totalmente.

- Intenção de agir: Quando é afirmado aos entrevistados que, dependendo da situação, eles poderiam agir da mesma maneira, 192 entrevistados discordaram de tal afirmação, sendo $64 \%$ totalmente.

- Oportunidade: Foi proposta uma situação em que há uma oportunidade para que o profissional de contabilidade cometesse o ato - troca da empresa de auditoria sendo dificilmente descoberto. Nesse aspecto, $89 \%$ dos entrevistados discordaram do comportamento oportunista do profissional, sendo que $76 \%$ discordaram totalmente.

- Flexibilidade: Foi apresesentado o trecho do pronunciamento técnico CPC 01 - Redução ao valor recuperável dos ativos " $A$ entidade deve avaliar, no mínimo, ao fim de cada exercício social, se há alguma indicação de que um ativo possa ter sofrido desvalorização. Se houver alguma indicação, a entidade deve estimar o valor recuperável do ativo". Afirmou-se que o referido trecho da norma é flexível.Aqui, 149 respondentes concordaram com a afirmação, sendo que $30 \%$ concordaram totalmente.

\subsubsection{Análise Multivariada dos dados}

$\mathrm{Na}$ análise estatística,buscou-se mensurar se os vértices do Modelo de Cressey (racionalização, oportunidade e pressão), as características individuais (idade, gênero, nível educacional, posição no mercado de trabalho, tipo de registro) influenciavam a intenção de agir dos profissionais de contabilidade quando se deparam com dilemas morais, envolvendo atos ilícitos em sua atividade profissionalno ambiente de convergência as normas internacionais de contabilidade, $\mathrm{e}$ ainda, se havia flexibilidade na escolha das práticas contábeis.

A tabela abaixo apresenta as variáveis que compõem o modelo e seus respectivos resultados estatísticos obtidos pela regressão multivariada efetuada.

Tabela 2: Regressão logística primeiro cenário proposto

\begin{tabular}{|c|c|c|c|c|c|c|}
\hline & $B$ & S.E. & Wald & Desvio padrão & Significância & $\operatorname{Exp}(B)$ \\
\hline Gênero & 2,78 & 1,40 & 3,94 & 1,00 & 0,05 & 0,06 \\
\hline Formação & 1,37 & 1,47 & 0,88 & 1,00 & 0,35 & 3,95 \\
\hline Técnico & 6,41 & $27.153,95$ & 0,00 & 1,00 & 1,00 & 606,99 \\
\hline Graduação & 10,99 & $27.153,95$ & 0,00 & 1,00 & 1,00 & $59.564,60$ \\
\hline Especialização & 13,97 & $27.153,95$ & 0,00 & 1,00 & 1,00 & $1.168 .320,20$ \\
\hline Mestre & 10,72 & $27.153,95$ & 0,00 & 1,00 & 1,00 & $45.159,86$ \\
\hline Empregador & 2,48 & 144,19 & 0,00 & 1,00 & 0,99 & 11,91 \\
\hline Setor privado & 2,15 & 2,08 & 1,06 & 1,00 & 0,30 & 0,12 \\
\hline Setor público & 0,51 & 2,33 & 0,05 & 1,00 & 0,83 & 1,66 \\
\hline Questão moral & 4,27 & 1,17 & 13,35 & 1,00 & 0,00 & 0,01 \\
\hline Julgamento ato & 2,98 & 1,17 & 6,48 & 1,00 & 0,01 & 0,05 \\
\hline Gravidade & 7,16 & 1,86 & 14,81 & 1,00 & 0,00 & $1.290,48$ \\
\hline Racionalização & 1,98 & 0,84 & 5,64 & 1,00 & 0,02 & 0,14 \\
\hline Pressão & 2,42 & 1,29 & 3,52 & 1,00 & 0,06 & 11,21 \\
\hline Oportunidade & 2,78 & 1,42 & 3,86 & 1,00 & 0,05 & 0,06 \\
\hline Constante & 25,33 & $81.461,99$ & 0,00 & 1,00 & 1,00 & 0,00 \\
\hline
\end{tabular}

Fonte: O autor, 2013 
Tabela 3: Regressão logística segundo cenário proposto

\begin{tabular}{|c|c|c|c|c|c|c|c|}
\hline & & B & S.E. & Wald & $\begin{array}{l}\text { Desvio } \\
\text { padrão }\end{array}$ & Significância & $\operatorname{Exp}(B)$ \\
\hline Gênero & - & 1,03 & 0,68 & 2,25 & 1,00 & 0,13 & 0,36 \\
\hline Formação & - & 1,18 & 0,68 & 2,95 & 1,00 & 0,09 & 0,31 \\
\hline Técnico & & 15,08 & $28.115,87$ & 0,00 & 1,00 & 1,00 & $3.554 .211,95$ \\
\hline Graduação & & 17,90 & $28.115,87$ & 0,00 & 1,00 & 1,00 & $59.171 .325,58$ \\
\hline Especialização & & 16,51 & $28.115,87$ & 0,00 & 1,00 & 1,00 & $14.816 .634,43$ \\
\hline Mestre & & 17,64 & $28.115,87$ & 0,00 & 1,00 & 1,00 & $45.779 .504,40$ \\
\hline Empregador & & 0,71 & 3,37 & 0,04 & 1,00 & 0,83 & 2,03 \\
\hline Setor privado & - & 0,01 & 1,38 & 0,00 & 1,00 & 0,99 & 0,99 \\
\hline Setor público & & 0,88 & 1,55 & 0,32 & 1,00 & 0,57 & 2,41 \\
\hline Questão moral & - & 1,57 & 0,53 & 8,74 & 1,00 & 0,00 & 0,21 \\
\hline Julgamento ato & - & 0,28 & 0,52 & 0,29 & 1,00 & 0,59 & 0,76 \\
\hline Gravidade & - & 0,23 & 0,51 & 0,20 & 1,00 & 0,65 & 0,80 \\
\hline Racionalização & & 0,68 & 0,36 & 3,53 & 1,00 & 0,06 & 1,97 \\
\hline Pressão & & 0,02 & 0,35 & 0,00 & 1,00 & 0,95 & 1,02 \\
\hline Oportunidade & & 0,32 & 0,52 & 0,38 & 1,00 & 0,54 & 1,38 \\
\hline Constante & - & 29,59 & $89.007,03$ & 0,00 & 1,00 & 1,00 & 0,00 \\
\hline
\end{tabular}

Fonte: 0 autor, 2013

De acordo com os resultados obtidos, em relação ao triângulo de Cressey, duas variáveis apresentaram significância estatística no primeiro cenário proposto $(p<0,05)$, influenciando a intenção de agir no posicionamento ético dos profissionais de contabilidade no cenário proposto, quando se deparam com dilemas morais, envolvendo atos ilícitos em sua atividade profissional. A influência das variáveis oportunidade e racionalização está em concordância com estudos anteriores (Choo e Tan (2007); Silva (2009)). Em relação à oportunidade, Choo e Tan (2007) argumentam que os gestores irão buscar ativamente maneiras de criar meios de burlar os mecanismos institucionais criados para coibir a fraude, mesmo que as oportunidades não estejam presentes. No tocante à racionalização, Choo e Tan (2007) citam que é mais fácil admitir a fraude como uma maneira aceitável de alcançar o sucesso quando há um ambiente social e corporativo em que o lucro é perseguido a qualquer custo.

Em relação às características individuais, somente a variável gênero apresentou significância estatística no primeiro cenário proposto $(p<0,05)$, figurando como possível influência na intenção de agir no posicionamento ético dos profissionais de contabilidade quando se deparam com dilemas morais, envolvendo atos ilícitos em sua atividade profissional. Esta variável, de acordo comestudos anteriores (Cole e Smith (1996); Silva (2009)), normalmente não apresenta influência na tomada de decisão do indivíduo.

A variável flexibilidade não apresentou significância estatística, não influenciando a intenção de agir no posicionamento ético dos profissionais de contabilidade quando se deparam com dilemas morais, envolvendo atos ilícitos em sua atividade profissionalno ambiente de convergência as normas internacionais de contabilidade.

O teste VIF apontou que a colinearidade foi inferior a 10,0, não apontando presença de significativa de colinearidade entre as variáveis independentes. Os testes de Omnibus foram estatisticamente significativos (valor $p<0,05$ ), enquanto que o teste de Hosmer e Lemeshow apresentou significância estatística adequada (valor $p>0,05$ ), demonstrando que as diferenças entre os 
valores observados e previstos são poucas. A combinação do teste de Hosmer e Lameshow com o teste geral do modelo de Omnibus fornece suporte para a aceitação do modelo (HAIR 2005), demonstrando que o modelo de regressão logística é significativo e adequado para o exame de suas variáveis.

\section{CONSIDERAÇÕES FINAIS}

Em decorrência do pouco tempo transcorrido, a partir das mudanças na legislação contábil e do número reduzido de pesquisas efetuadas em relação à conduta ética dos profissionais de Contabilidade, diante do cenário de convergência às Normas Internacionais de Contabilidade, Silva (2009) buscou avaliar os procedimentos destes profissionais, abordando questões, que dizem respeito às fraudes e aos fatores de influência no processo decisório ético dos indivíduos. Alves (2005) procurou conhecer as percepções da classe contábil quanto aos princípios, os deveres, as obrigações e as sanções contidas no código de ética da profissão. Estes trabalhos foram motivadores para a elaboração da presente pesquisa.

Este estudo buscou adentrar no ambiente de mudanças da legislação contábil, tendo como objetivo abordar a intenção de agir no posicionamento ético do profissional de contabilidade em relação aos dilemas morais, envolvendo atos ilícitos no exercício de suas atividades profissionais, neste novo ambiente de convergência aos padrões internacionais de contabilidade.

Os testes estatísticos utilizados corroboraram com o demonstrado no Modelo de Cressey na medida em que sugeriram que, nos cenários propostos, os profissionais de contabilidade podem se aproveitar de um momento de troca da empresa de auditoria para efetuar ajustes, que beneficiarão o resultado da Companhia (Oportunidade), tentando justificar este procedimento pelo fato de ser uma prática comum no mercado (Racionalização), na tentativa de transformar algo antiético em algo aceitável.

Pôde-se verificar, também, que a variável julgamento do ato e a variável gravidade do ato foram estatisticamente significantes. $O$ julgamento do ato corresponde à avaliação moral que o indivíduo faz para estabelecer se determinada conduta é ética ou antiética, a partir da sua percepção sobre a gravidade da falta. A gravidade reflete a sensibilidade do indivíduo no processo decisório, levando em consideração os valores, as crenças, as necessidades, as maneiras de ver os acontecimentos, conforme destacado no referencial teórico, possibilitando diferentes interpretações a respeito das questões éticas por parte destes indivíduos. O reconhecimento da questão moral corresponde à capacidade do indivíduo de reconhecer o aspecto moral implícito nos cenários propostos.

Por fim, a não aceitação da hipótese da flexibilidade influenciar a intenção de agir dos profissionais de contabilidade diverge de Oliveira e Bispo (2009, p.2), os quais afirmaram que "[...] os gestores podem, por exemplo, utilizar escolhas contábeis por razões oportunistas, gerando conflitos nas organizações que acabam por interferir no resultado da empresa [...]".

Considera-se como limitações da pesquisa a restrição dos resultados obtidos em apenas dois cenários específicos, a não inferência estatística da amostra para a população, e a pouca experiência de vida e profissional dos respondentes dos questionários, cuja média de idade foi de 32 anos, sendo um potencial ponto fraco desta pesquisa. Caso a média de idade fosse outra, os resultados poderiam ser divergentes. Sendo assim, este estudo contribuiu para um maior entendimento do impacto das mudanças das normas contábeis, no tocante ao processo decisório ético dos profissionais de contabilidade. A fim de ampliar as pesquisas referentes ao tema em questão, sugere-se investigar a conduta ética dos profissionais de contabilidade em empresas reguladas pelo governo, empresas de capital fechado e empresas familiares. 
TESTANDO O TRIÂNGULO DE CRESSEY NO CONTEXTO DA CONVERGÊNCIA ÀS NORMAS INTERNACIONAIS DE CONTABILIDADE: UM ESTUDO EMPÍRICO SOBRE COMPORTAMENTO ÉTICO DE PROFISSIONAIS DE CONTABILIDADE

\section{REFERÊNCIAS}

ALMEIDA, Sidmar Roberto Vieira; COSTA, Thiago de Abreu; SILVA, Adolfo Henrique Coutinho e. Análise dos Impactos das Normas Internacionais de Contabilidade Sobre o Lucro Líquido e o Patrimônio Líquido das Empresas de Extração e Processamento de Recursos Naturais. In: Congresso nacional de Administração e Ciências Contábeis- ADCONT, 2., 2011, Rio de Janeiro.

ALVES, Francisco José dos Santos. Adesão do Contabilista ao código de ética da sua profissão:Um estudo empírico sobre percepções. 2005. 265p. Tese (doutorado) Universidade de São Paulo - USP. São Paulo, 2005.

AMAT, O.; MOYA, S; BLAKE, J. La Contabilidad Creativa.Partida Doble, n.79, p.24-32, junio 1997.

ARRUDA, Giovana Silva de; MADRUGA, Sergio Rossi.; JUNIOR, Ney Izaguirry de Freitas. A Governança Corporativa e a Teoria da Agência em consonância com a Controladoria. Revista de Administração UFSM, Santa Maria, v. 1, n. 1, p.71-84, jan./abr.2008.

BECKER, Howard. Segredos e truques da pesquisa. Rio de Janeiro: Jorge Zahar, 2007.

BRASIL. Lei n. 6.404/76. Disponível em<http://www.planalto.gov.br/ccivil_03/ leis/L6404compilada.htm>. Acesso em 01/05/2012.

BRASIL. Lei n. 11.638 de 28 de dezembro de 2007. Disponível em<http://www.planalto. gov.br/ccivil_03/_ato2007-2010/2007/lei/ |11638.htm>. Acesso em 01/05/2012.

CHOO, Freddie; TAN Kim.An "American Dream" theory of corporate executive Fraud. Accounting Forum 31 (2007) 203-215.

COLE, Bárbara C.; SMITH, DennieL.. Perceptions of business ethics: Students vs. business people. Journal of Business Ethics; 15: 889896; ABI/INFORM Global; Aug 1996.

COLLIS, Jill; HUSSEY, Roger. Pesquisa em Administração: um guia prático para alunos de graduação e pós-graduação. 2. ed. Porto Alegre: Bookman, 2005.

Conselho Federal de Contabilidade. Resolução CFC № 836/1999.Aprova a NBC T 11 - IT 3 Fraude e erro. Disponível em: http://www.cfc. org.br/resolucoes_cfc/RES_836.DOC. Acesso em: 01 de maio 2012

COOPER, Donald R.; SCHINDLER, Pamela S. Métodos de Pesquisa em Administração.7. ed. Porto Alegre : Bookman, 2003.

CRESSEY, D. R.; MOORE, C. A. Managerial Values and Corporate Codes of Ethics.California Management Review. CA, v. 25, n. 4, p. 53-77, Summer 1983.

DECONINCK, James B.; LEWIS, William F..The Influence of Deontological and Teleological Considerations and Ethical Climate on Sales Managers' Intentions to Reward or Punish Sales Force Behavior.Journal of Business Ethics 16: 497- 506, 1997.C 1997 Kluwer Academic Publishers.Printed in the Netherlands.

DOUGLAS, Patricia Casey; DAVIDSON, Ronald A.; SCHWARTZ, Bill N..The Effect of Organizational Culture and Ethical Orientation on Accountants' Ethical Judgments.Journal of Business Ethics. 34: 101-121, 2001. (c) 2001 Kluwer Academic Publishers.Printed in the Netherlands.

FERREL, O. C.; FRAEDRICH, J.; FERREL, L..Ética Empresarial.4a ed.. Reichmann\& Affonso Ed., 2001.

GOLES, Tim; WHITE, Gregory B.; BEEBE, Nicole; DORANTES, Carlos A.; HEWITT, Barbara. Moral Intensity and Ethical Decision-Making: A Contextual Extension.The data base for Advances in Information Systems. v.37, n. 2-3, 2006. 
HAIR Jr., Joseph F.; BABIN, Barry; MONEY, Arthur H.; SAMOUEL, Phillip.Fundamentos de Métodos de Pesquisa em Administração. Porto Alegre: Bookman, 2005.

LEVINE, D. M.; et al. Estatística: teoria e aplicações. 5. ed. Rio de Janeiro: TLC, 2008. $752 \mathrm{p}$.

MARTINEZ, Antonio Lopo. Gerenciamento dos resultados contábeis: estudo empírico das companhias abertas brasileiras. 2001. 153 fl. Tese (Doutorado em Ciências Contábeis), Departamento de Contabilidade e Atuária da Faculdade de Economia, Administração, e Contabilidade da Universidade de São Paulo, São Paulo, 2001.

MARTINS, Eliseu; MARTINS, Vinícius A.; MARTINS, Éric A. Normatização contábil: ensaio sobre sua evolução e o papel do CPC. Revista de Informação Contábil: RIC/UFPE, Pernambuco, v. 1, n. 1, p.7-30, set.2007.

MATSUMOTO, A. S; PARREIRA, E. M. Uma pesquisa sobre o Gerenciamento de Resultados Contábeis: causas e conseqüências. UnB Contábil - UnB, Brasília, vol. 10, no 1, jan/jun $-2007$.

MINAYO, M. C. S. O desafio do conhecimento: pesquisa qualitativa em saúde. São Paulo: Hucitec, 2004.

OLIVEIRA, Gideão José Pinto ; BISPO, Oscar neto de Almeida.Qualidade da Auditoria e Gerenciamento de Resultados Contábeis em Initial Public Offering (IPO).XII SEMEAD Empreendedorismo e inovação, 2009.

PEREIRA, Breno A. Diniz; LOBLER, Mauri Leodir.; SIMONETTO, Eugênio de Oliveira. Análise dos modelos de tomada de decisão sob o enfoque cognitivo. Revista de Administração UFSM, Santa Maria, v. 3, n. 2, p.260-268, mai./ ago.2010.

SANTOS, Edilene Santana. Análise dos impactos dos CPCs da primeira fase de transição para o IFRS nas empresas abertas: um exame censitário dos ajustes ao resultado nas DFPs de 2008. In: ENANPAD, 34, 2010, Rio de Janeiro. Anais... Rio de Janeiro: ANPAD, 2010.

SILVA, Aline Moura Costa da.Atitude do Profissional de Contabilidade em relação à fraude:uma abordagem apoiada em cenários. 2009. 159p.Dissertação (Mestrado) - Faculdade de Administração e Finanças, Universidade do Estado do Rio de Janeiro UERJ. Rio de Janeiro, 2009.

SINGLETON, Tommie W.; SINGLETON, Aaron, J.; BOLOGNA, G. Jack;LINDQUIST, Robert J..Fraud auditing and forensic accounting. New Jersey: John Wiley \& Sons, 2006.

SUNDER, Shyam. Knowing what others know: common knowledge, accounting and capital markets. Journal of Management Accounting Research. v. 16, p. 305-319, 2002. 